\title{
Self-awareness and social self-supervision in online transportation industry
}

\author{
Olfebri $^{a}$, Agus Suroso ${ }^{a}$, Refius Pradipta Setyanto ${ }^{a}$ and M. Elfan Kaukab ${ }^{b^{*}}$
}

${ }^{a}$ Faculty of Economics and Business, Universitas Jenderal Soedirman, Purwokerto, Indonesia

${ }^{b}$ Faculty of Economics and Business, Universitas Sains Al-Qur'an, Wonosobo, Indonesia

\section{H R O N I C L E}

\begin{tabular}{l}
\hline Article history: \\
Received: March 21, 2021 \\
Received in revised format: April \\
25,2021 \\
Accepted: May 2, 2021 \\
Available online: May 2, 2021 \\
\hline Keywords: \\
Online transportation \\
Self-awareness \\
Self-supervision
\end{tabular}

\section{A B S T R A C T}

Online transportation has widely spread across the globe in the past three years. It provokes changes in transportation management. Driver's quality improvement is crucial to prevent problems related to accidents and driver-passenger relationships. This paper employs regression analysis to identify the effect of driving attitude, self-awareness, and social self-supervision on aberrant driving behavior in online taxi drivers in Indonesia. One hundred Grab and Go-Jek drivers are selected from the DKI Jakarta area. Data are collected via questionnaires. Data analysis, as well as statistical calculation, reveals the negative effects of social self-supervision on aberrant driving behavior.

\section{Introduction}

Aberrant driving behavior is driving with attention and memory failures, errors, and violations (Huang, Lin, \& Wang, 2018). It manifests in various things, such as failure in keeping road users' safety, ineffective and inefficient driving, and traffic violations (Reason, Manstead, Stradling, Baxter, \& Campbell, 1990). Generally, male drivers are more likely to have aberrant driving than female ones (Chan, Wu, \& Hung, 2010; Elliott, Armitage, \& Baughan, 2003). Studies on aberrant driving behavior reveal that overconfidence and alcohol consumption are its causes (Chan et al., 2010). Positive attitudes, subjective norms encouraging rule-abiding behavior, and difficulty to violate rules are three inhibitors of aberrant driving behavior (Bordarie, 2019; Elliott et al., 2003). Situations prompting drivers to engage in aberrant driving include lateness to work or school (Hassan, 2016), neurotic personality (Shen, Qu, Ge, Sun, \& Zhang, 2018), and inexperience (Rezapur-Shahkolai, Taheri, Etesamifard, Roshanaei, \& Shirahmadi, 2020). The most common behavior is switching the radio and listening to music while driving. Cut through slow cars and ride above the speed limit are also forms of deviant behavior. Deviant drivers endanger themselves, their passengers, and other road users (Yan Wang \& Chen, 2020). Research suggests that traffic violations and mistakes lead to accidents (Parker, West, Stradling, \& Manstead, 1995). Violations and attention failures risk the drivers to have severe accidents, while errors lead them to minor ones (Parker, Reason, Manstead, \& Stradling, 1995). Drivers' awareness has a crucial role in certain deeds. Awareness is one of the mental processes (Kaukab, Adawiyah, Setyanto, \& Suroso, 2020). It is different from others, such as cognition, motive, and emotion. It consists of vigilance and attention. Full awareness is an attentive and vigilant state of the surrounding events (Brown \& Ryan, 2003). Vigilance is a background condition where a person constantly observes his internal and external environment. Meanwhile, attention is a process of focusing on alertness to be more sensitive to experience (Westen, 1998). Self-awareness is an inhibitor of aggressive driving behavior (Shen et al., 2018; Stephens, Koppel, Young, Chambers, \& Hassed, 2018). A study has shown that those driving in high alertness have less deviant behavior and are less likely involved in accidents as well as traffic violations (Koppel et al., 2018). On the contrary, drivers whose focuses are not on the present time (for example, they think about the past or imagining of the future) are prone to aberrant driving behavior (Yuchen Wang, Qu, Ge, Sun, \& Zhang, 2018).

* Corresponding author. Tel.: +628156685076

E-mail address: elvankaukab@yahoo.com (M. Elfan Kaukab) 
Social self-supervision is a concept drawn by the writer from the public self-supervision (Hayati, Suroso, \& Kaukab, 2020). It is a situation in which a person is aware of how other people perceive them and how he/she performs in public (Huang et al., 2018). People with high public self-awareness behave in a way that will earn them rewards and appreciation, and at the same time avoid rejection or negative behavior from others (Doherty \& Schlenker, 1991). To keep public recognition, that person needs to make sure that he/she performs in accordance with his/her role. It can be friendliness, control, and politeness to other people, including the passengers (Huang et al., 2018). Literary review denotes that a person who controls him/herself all the time, especially when other people are around, is more obedient to the norms, including the driving ones (Millar, 2007). In contrast, someone incapable of socially watching him/herself is unable to control positive behavior to other people, or simply cares for no one, tends to show aberrant driving behavior (Huang et al., 2018). Attitude is someone's cognitive and emotional evaluation of an act (Ajzen, 1991). It might be an opinion that it is good, meticulous, proper, rational, responsible, and such. Attitude is an antecedent of intention and behavior (Fishbein \& Cappella, 2006), which mediates a person's characteristics and behavior (Ajzen, 1991). It is a crucial element of the planned behavior theory. There are some proofs that attitude has a role in driving behavior. A study found that a positive attitude towards illegal races tends to make someone get involved in this deviant behavior (Li, Shi, Liu, \& Wang, 2016). Another one showed that attitude mediates anger personality with aggressive and common violations when driving (Gaianu, Giosan, \& Sârbescu, 2020). One study by Bazargan-Hejazi et al. (Bazargan-Hejazi et al., 2017) revealed that it is the strongest predictor of cellphone texting while driving. Up to now, there are a limited untested number of researches analyzing self-awareness, social self-supervision, and attitude that influence aberrant driving behavior. Huang et al. (Huang et al., 2018) suggested the importance of specific research on drivers of a particular type of vehicle, especially taxis.

This research seeks to explore the relation of self-awareness, social self-supervision, attitude, and aberrant driving behavior. We suspect that drivers with high self-awareness, big social self-supervision, and a good attitude will report lower aberrant driving behavior.

\section{Hypothesis}

A good driving requires high alertness to the surrounding environment to avoid deviant behavior. We predict that self-awareness negatively affects aberrant driving behavior since it lowers aggressiveness and aggressive behavior (Fix \& Fix, 2013). Aggressive drivers tend to get involved in deviant behavior (Deffenbacher, Lynch, Oetting, \& Swaim, 2002). Meanwhile, drivers with high self-awareness have better situational perception and less participation in accidents (Kass, VanWormer, Mikulas, Legan, \& Bumgarner, 2011). Self-awareness enables a person to evaluate his/her experience and reaction (Wright, Day, \& Howells, 2009). Thus:

\section{$\mathbf{H}_{1}$ : There is a negative effect of self-awareness to aberrant driving behavior.}

Literature has been debating whether the passenger is the source of stress, distraction, and risk-elevator (Chen, Baker, Braver, $\& \mathrm{Li}, 2000$ ) or the supervisor, which allows lower accident risk (Huang et al., 2018). Recent studies using the public selfawareness theory found that passengers are supervisors preventing aberrant driving behavior (Huang et al., 2018). Drivers will conform him/her role to his/her passenger and be attentive towards his/her behavior in providing service for his/her. Therefore, we predict that social self-supervision will control driving behavior.

$\mathbf{H}_{2}$ : Social self-supervision negatively affects aberrant driving behavior.

The planned behavior theory (Ajzen, 1991) sees attitude as a crucial element of behavior. Research shows that it is a behavior proxy variable to prevent accidents (George, 2016). It is a foundation of intention, expressed through driving behavior (Beullens, Roe, \& Van den Bulck, 2011). Based on this logic, we predict that:

\section{$\mathbf{H}_{3}$ : Good driving attitude negatively affects aberrant driving behavior.}

\section{Methods}

Participants of this research are 100 drivers aged between 20 to 40 from various online transportation in Jakarta, Indonesia. They are chosen because they drive cars on a daily basis to take passengers to their destinations. All are male, and $61 \%$ are married. The self-awareness scale is a questionnaire containing five items on the Likert scale, ranging from 1 (never) to 5 (almost always). The participants chose the frequency of optimum self-awareness when driving. The scale shows internal consistency (Cronbach's alpha 0.784). It is a development of Brown's and Ryan's (Brown \& Ryan, 2003). The scale of social self-supervision is a four-item questionnaire on the Likert's, stretching from 1 (never) to 5 (almost always). Participants selected the most favorable frequency of social self-supervision to the passengers. The scale, which is a modification from Dewa's (Dewa, 2018), displays internal consistency (Cronbach's alpha 0.715). The scale of driving is a three-item questionnaire on the Likert's, from 1 (highly disagree) to 5 (highly agree). It asks whether the participants agree to the statements related to driving behavior. The scale, which is developed from George's (George, 2016), displays internal consistency (Cronbach's alpha 0.715). The scale of aberrant driving behavior is a six-item questionnaire which is answered also in Likert's 1 (never) to 5 (almost always). The participants decide their frequency of having troubles when driving. It also shows internal consistency (Cronbach's alpha 0.656) and is an expansion of Huang et al. (Huang et al., 2018). Table 1 displays the means and standard deviations of each item. 
Table 1

Detailed information of the survey items

Construct/indicator: possible range 1 to 5

Self-awareness

\begin{tabular}{lc} 
I tend to walk fast to my destination without noticing what I experience along the way & 1.62 \\
\hline I
\end{tabular}

I do things in a hurry without paying careful attention to them $1.57 \quad 0.61$

I do my activities automatically; I am not are of what I am doing $\quad 1.45 \quad 0.58$

I listen to other people while doing something at the same time $r \begin{array}{ll}1.59 & 0.62\end{array}$

I drive mechanically and get confused about how I get to a place $\quad 1.57 \quad 0.57$

Social self-supervision

\begin{tabular}{lr} 
Make efforts to provide the best service to the customers & 4.35 \\
\hline
\end{tabular}

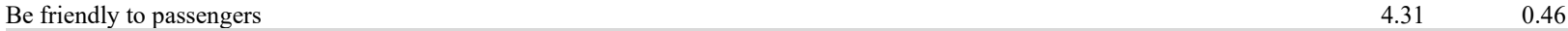

$\begin{array}{lr}\text { Adept in helping passengers } & 4.19 \\ \text { Com } & 0.42\end{array}$

$\begin{array}{lr}\text { Comfort and guarantee the worried passengers' safety } & 4.27 \\ \text { Driving bes }\end{array}$

Driving behavior

Driving by the rules means making good choices 0.50

Driving by the rules is the right thing to do $\quad 0.64$

Aberrant driving behavior

I forget where I park my car in multilevel parking lot 0.58

I think about other things and get distracted when I realize the car ahead slows down, and I have to brake hard to avoid accident 1.51

I ignore traffic rules and almost hit the vehicles from the opposite direction. 0.51

I almost hit a bike when make a turn $\quad 0.47$

I am engaged in speeding in the road $\quad 0.51$

I park in a forbidden lot

1.510 .50

The questionnaires obtain information from online taxi drivers who had agreed to participate in this research. Before filling them out, we informed the respondents to leave their names out and that their answers are confidential. They should not worry that the questionnaires are for their partner companies' interests.

\section{Results}

Table 2 displays the means and standard deviations of driving attitude, self-awareness, social self-supervision, and aberrant driving behavior. The results show that participants have a minimum aberrant driving behavior and self-unawareness. On the other hand, they have good social self-supervision and a positive-safe driving attitude.

Table 2

The means and standard deviations of driving attitude, self-awareness, social self-supervision, and deviant behavior

\begin{tabular}{|c|c|c|}
\hline & Mean & Standard deviation \\
\hline Aberrant driving behavior & 1.50 & 0.31 \\
\hline Self-awareness & 1.56 & 0.46 \\
\hline Social self-supervision & 4.27 & .0 .48 \\
\hline Attitude & 4.30 & 0.50 \\
\hline
\end{tabular}

The computation of bivariate correlation tests the correlation between aberrant driving behavior and other variables. They are self-awareness $\left(\mathrm{r}=0.51^{* *}\right)$, social self-supervision $\left(\mathrm{r}=-0.68^{* *}\right)$, and attitude, all of which are significant $(\mathrm{r}=-0.39 * *)$.

Table 3

The bivariate correlation between attitude (A), social self-supervision (SS), self-awareness (SA), and aberrant driving behavior $(\mathrm{ADB})$

\begin{tabular}{|c|c|c|c|c|}
\hline & ADB & SA & $\mathrm{SS}$ & ADB \\
\hline \multicolumn{5}{|l|}{ Aberrant driving behavior } \\
\hline Self-awareness & $0.51 * *$ & & & \\
\hline Social self-supervision & $-0.68 * *$ & $-0.76 * *$ & & \\
\hline Attitude & $-0.39 * *$ & $-0.72 * *$ & $0.68 * *$ & \\
\hline
\end{tabular}

The table shows the correlation between aberrant driving behavior, self-awareness, social self-supervision, and attitude. Overall, the variables significantly correlated with each other. The linear regression analysis evaluates the predictor of aberrant driving behavior (Table 4). The results prove that social self-supervision significantly affects aberrant driving behavior, while self-awareness and attitude do not. The predictor elaborates on $46 \%$ variants of aberrant driving behavior.

\section{Table 4}

Attitude (A), social self-supervision (SS), and self-awareness (SA) as the predictors of aberrant driving behavior (ADB)

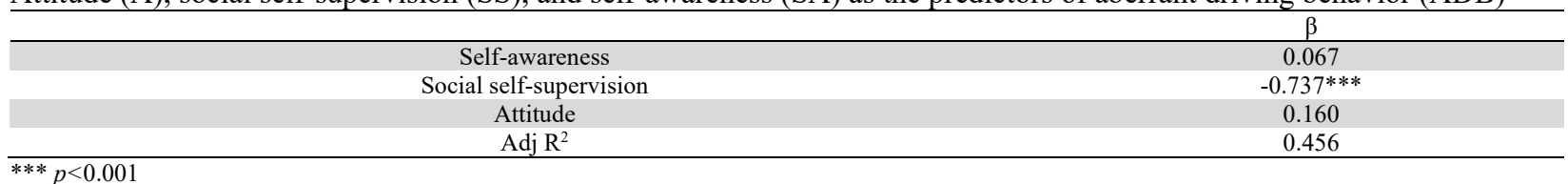




\section{Discussion}

The literature of aberrant driving behavior has been explored for a long time (Bordarie, 2019). Most studies examine the psychological predictors aiming to oneself (Elliott et al., 2003; Li et al., 2016), mostly because they assume that drivers do not take into account other people in their vehicles (Singh, Rapheileng, \& Singh, 2016). The review of the factors controlling aberrant driving highlights those such as self-awareness (Aghabayk, Mashhadizade, \& Moridpour, 2020) and attitude (Batool \& Carsten, 2018). However, there are now interests in social factors influencing aberrant driving behavior, especially in public transportation drivers (Gershon, Zhu, Klauer, Dingus, \& Simons-Morton, 2017; Huang et al., 2018; Millar, 2007; Xu et al., 2016).

This research reveals a significant negative correlation between social self-awareness and aberrant driving behavior. It suggests that drivers have higher social self-supervision keeping them from involving in aberrant driving behavior. They are aware of the fact that drivers carrying passengers face social pressure to behave properly, which leads to them driving safely and obediently (Millar, 2007). The insignificant effect of self-awareness and attitude variables to aberrant driving confirms that the psychological factors are not as strong as the social factors in affecting drivers' behavior. It is analogous to the model of public self-awareness (Huang et al., 2018), in which attitude in front of the public largely determines the behavior. Other people's presence provokes a person's need to be accepted in the form of good service and a positive rate from the passenger. Public self-awareness might overcome the psychological aspect, such as anxiety (Dula, Adams, Miesner, \& Leonard, 2010). It shows that social self-awareness controls driving behavior.

The insignificant effects of attitude and self-awareness contradict the findings of the previous study (Koppel et al., 2018) on 318 drivers, which found that self-awareness negatively affects aberrant driving behavior. It is probably due to the similarity of the sample drivers (Batool \& Carsten, 2018) or the mediating variable connecting self-awareness with aberrant driving behavior, such as emotional intelligence (Heidaryan, Alimohammadi, Vosoughi, \& Abolghasemi, 2020; Stephens et al., 2018). Further research is necessary and includes a mediating variable that bridges the attitude and self-awareness to aberrant driving behavior (Sani, Tabibi, Salehi, \& Stavrinos, 2017). Drivers are individuals relying on social as well as emotional aspects, and thus, the psychologically characterized research is essential (Aghabayk et al., 2020).

Shen et al. (Shen et al., 2018) stated that good driving behavior leads to a smooth journey and provides safety for the driver, passengers, and other road users. Ozkan and Lajunen (2006) suggested that it makes people care about the traffic environment and show courtesy by driving calmly and humbly. Therefore, good driving behavior brings more advantages to the community.

\section{Conclusion}

This research aims to confirm the hypothesis that self-awareness, social self-supervision, and attitude negatively affect aberrant driving behavior in Jakarta city. It proves that only the social self-supervision variable meets the hypothesis. The fact is self-awareness and attitude do not significantly affect aberrant driving behavior in online transportation. The analysis has also shown that the three variables contributed to $45,6 \%$ of the variants of aberrant driving behavior in the online Jakarta transportation industry.

Therefore, we propose some practical implications. One, online transportation needs to have a training and development program to increase their drivers' quality. It seeks to develop their responsiveness, service provision, friendliness, and the best service to the passengers. Two, the online transportation industry should have better recruitment criteria. The potential drivers must exhibit their ability in providing the service for passengers, responding to demands, calming the anxious passengers, and ensuring passengers' safety. Three, the government ought to make policies that prevent drivers from aberrant driving behavior. They can be an information campaign policy combined with infrastructure quality development. The first one includes billboards informing the allowed parking lot along with the fine for violating it that are equipped with camera or sensor, warning signs forbidding driving over the speed limits together with the sanction and fatal consequences, information of the bike's line and frequency with clear limit, midway divider preventing vehicles to cut from the opposite direction, and clear parking lot signs.

The recommendations benefit the drivers, road users, and the community at large. They will be safer as aberrant driving behavior declines. Members of society feel more comfortable using online transportation. They are also encouraged to have sustainable transportation activities, such as biking.

\section{References}

Aghabayk, K., Mashhadizade, L., \& Moridpour, S. (2020). Need Safer Taxi Drivers ? Use Psychological Characteristics to Find or Train! Sustainability, 12(4206), 1-11.

Ajzen, I. (1991). The theory of planned behavior. Orgnizational Behavior and Human Decision Processes, 50, $179-211$. https://doi.org/10.1016/0749-5978(91)90020-T

Batool, Z., \& Carsten, O. (2018). Attitudinal segmentaion of drivers in Pakistan: The potential for effective road safety campaigns. Accident Analysis and Prevention, 114, 48-54.

Bazargan-Hejazi, S., Teruya, S., Pan, D., Lin, J., Gordon, D., Krochalk, P., \& Bazargan, M. (2017). The Theory of Planned Behavior (TPB) and Texting While Driving Behavior in College Students. Traffic Injury Prevention, 18(1), 56-62. https://doi.org/10.1080/15389588.2016.1172703.The 
Beullens, K., Roe, K., \& Van den Bulck, J. (2011). Excellent gamer, excellent driver? The impact of adolescents' video game playing on driving behavior: a two-wave panel study. Accident Analysis and Prevention, 45, 58-65. https://doi.org/10.1016/j.aap.2010.07.011.Published

Bordarie, J. (2019). Predicting intentions to comply with speed limits using a ' decision tree' applied to an extended version of the theory of planned behaviour. Transportation Research Part F: Psychology and Behaviour, 63, 174-185.

Brown, K. W., \& Ryan, R. M. (2003). The Benefits of Being Present : Mindfulness and Its Role in Psychological Well-Being. Journal of Personality and Social Psychology, 84(4), 822-848. https://doi.org/10.1037/0022-3514.84.4.822

Chan, D. C. N., Wu, A. M. S., \& Hung, E. P. W. (2010). Invulnerability and the intention to drink and drive : An application of the theory of planned behavior. Accident Analysis and Prevention, 42, 1549-1555. https://doi.org/10.1016/j.aap.2010.03.011

Chen, L.-H., Baker, S. P., Braver, E. R., \& Li, G. (2000). Carrying Passengers as a Risk Factor for Crashes Fatal to 16- and 17-Year-Old Driver. JAMA, 283(12), 1578-1582.

Deffenbacher, J. L., Lynch, R. S., Oetting, E. R., \& Swaim, R. (2002). The Driving Anger Expression Inventory : a measure of how people express their anger on the road. Behaviour Research and Therapy, 40, 717-737.

Dewa, C. B. (2018). Pengaruh Kualitas Pelayanan dan Promosi Penjualan Jasa Grabcar Terhadap Kepuasan Pelanggan ( Studi Kasus Pada Wisatawan di Yogyakarta ). Perspektif, 16(1), 1-6.

Doherty, K., \& Schlenker, B. R. (1991). Self-Consciousness and Strategic Self-Presentation. Journal of Personality, 59(1), $1-19$.

Dula, C. S., Adams, C. L., Miesner, M. T., \& Leonard, R. L. (2010). Examining relationships between anxiety and dangerous driving. Accident Analysis and Prevention, 42, 2050-2056. https://doi.org/10.1016/j.aap.2010.06.016

Elliott, M. A., Armitage, C. J., \& Baughan, C. J. (2003). Drivers' Compliance with Speed Limits: An Application of the Theory of Planned Behavior. Journal of Applied Psychology, 88(5), 964-972.

Fishbein, M., \& Cappella, J. N. (2006). The Role of Theory in Developing Effective Health Communications. Journal of Communication, 56, 1-17. https://doi.org/10.1111/j.1460-2466.2006.00280.x

Fix, R. L., \& Fix, S. T. (2013). Aggression and Violent Behavior The effects of mindfulness-based treatments for aggression : A critical review. Aggression and Violent Behavior, 18, 219-227.

Gaianu, P.-A., Giosan, C., \& Sârbescu, P. (2020). From trait anger to aggressive violations in road traffic. Transportation Research Part F: Psychology and Behaviour, 70, 15-24. https://doi.org/10.1016/j.trf.2020.02.006

George, C. M. (2016). Supporting teen leaders : Validation of the I Drive Smart Survey. Virginia Commonwealth University.

Gershon, P., Zhu, C., Klauer, S. G., Dingus, T., \& Simons-Morton, B. (2017). Teens' distracted driving behavior: Prevalence and predictors. Journal of Safety Research, 63, 157-161. https://doi.org/10.1016/j.jsr.2017.10.002.Teens

Hassan, H. M. (2016). Investigation of the self-reported aberrant driving behavior of young male Saudi drivers : A surveybased study. Journal of Transportation Safety \& Security, 8(2), 113-128. https://doi.org/10.1080/19439962.2015.1017782

Hayati, S., Suroso, A., \& Kaukab, M. E. (2020). Customer satisfaction as a mediation between micro banking image, customer relationship and customer loyalty. Management Science Letters, 10, 2561-2570. https://doi.org/10.5267/j.msl.2020.3.039

Heidaryan, A., Alimohammadi, I., Vosoughi, S., \& Abolghasemi, J. (2020). Investigating the Effect of Emotional Intelligence Components on Driving Errors. Archives of Occupational Health, 4(2), 570-576.

Huang, Y., Lin, P., \& Wang, J. (2018). The influence of bus and taxi drivers ' public self-consciousness and social anxiety on aberrant driving behaviors. Accident Analysis and Prevention, 117, 145-153. https://doi.org/10.1016/j.aap.2018.04.014

Kass, S. J., VanWormer, L. A., Mikulas, W. L., Legan, S., \& Bumgarner, D. (2011). Effects of Mindfulness Training on Simulated Driving : Preliminary Results. Mindfulness, 2, 236-241. https://doi.org/10.1007/s12671-011-0066-1

Kaukab, M. E., Adawiyah, W. R., Setyanto, R. P., \& Suroso, A. (2020). Accelerating Small Firms ' Production Process Improvement Through International Market Knowledge And Valuable, Rare, Inimitable, And Organized Resources And Capabilities. Business: Theory and Practice, 21(1), 322-328.

Koppel, S., Stephens, A. N., Young, K. L., Hua, P., Chambers, R., \& Hassed, C. (2018). What is the relationship between self-reported aberrant driving behaviours, mindfulness and self- reported crashes and infringements? Traffic Injury Prevention, 19(5), 480-487. https://doi.org/10.1080/15389588.2018.1440083

Li, P., Shi, J., Liu, X., \& Wang, H. (2016). The Theory of Planned Behavior and Competitive Driving in China. Procedia Engineering, 137, 362-371. https://doi.org/10.1016/j.proeng.2016.01.270

Millar, M. (2007). The influence of public self-consciousness and anger on aggressive driving. Personality and Individual Differences, 43, 2116-2126. https://doi.org/10.1016/j.paid.2007.06.037

Ozkan, T., \& Lajunen, T. (2006). What causes the differences in driving between young men and women? The effects of gender roles and sex on young drivers ' driving behaviour and self-assessment of skills. Transportation Research Part F: Psychology and Behaviour, 9, 269-277. https://doi.org/10.1016/j.trf.2006.01.005

Parker, D., Reason, J. T., Manstead, A. S. R., \& Stradling, S. G. (1995). Driving errors, driving violations and accident involvement. Ergonomics, 38(5), 1036-1048.

Parker, D., West, R., Stradling, S., \& Manstead, R. (1995). Behavioural Characteristics and Involvement in Different Types of Traffic Accident. Accident Analysis and Prevention, 27(4), 571-581.

Reason, J., Manstead, A., Stradling, S., Baxter, J., \& Campbell, K. (1990). Errors and Violations on the Roads: A Real Distinction? Ergonomics, 33(10), 1315-1332.

Rezapur-Shahkolai, F., Taheri, M., Etesamifard, T., Roshanaei, G., \& Shirahmadi, S. (2020). Dimensions of aberrant driving behaviors and their association with road traffic injuries among drivers. PLoS ONE, 15(9), 1-16. 
https://doi.org/10.1371/journal.pone.0238728

Sani, S., Tabibi, Z., Salehi, J., \& Stavrinos, D. (2017). Aggression , emotional self-regulation , attentional bias , and cognitive inhibition predict risky driving behavior. Accident Analysis and Prevention, $109,78-88$. https://doi.org/10.1016/j.aap.2017.10.006

Shen, B., Qu, W., Ge, Y., Sun, X., \& Zhang, K. (2018). The relationship between personalities and self-report positive driving behavior in a Chinese sample. PLoS ONE, 13(1), 1-16.

Singh, K. T., Rapheileng, A., \& Singh, K. (2016). Self-Report Driver Stress and Aberrant Behavior. Anweshan, 4(1), 1-27.

Stephens, A. N., Koppel, S., Young, K. L., Chambers, R., \& Hassed, C. (2018). Associations between self-reported mindfulness , driving anger and aggressive driving. Transportation Research Part F: Psychology and Behaviour, 56, 149155. https://doi.org/10.1016/j.trf.2018.04.011

Wang, Yan, \& Chen, Q. (2020). Case study of road rage incidents resulting from the illegal use of high beams. Transportation Research Interdisciplinary Perspectives, 7, 1-8. https://doi.org/10.1016/j.trip.2020.100184

Wang, Yuchen, Qu, W., Ge, Y., Sun, X., \& Zhang, K. (2018). Effect of personality traits on driving style : Psychometric adaption of the multidimensional driving style inventory in a Chinese sample. PLoS ONE, 13(9), 1-17.

Westen, D. (1998). Unconscious thought, feeling and motivation: The end of a century-long debate. In R. Bornstein \& J. Mesling (Eds.), Empirical perspectives on the psychoanalytic unconscious (pp. 1-43). Washington DC: American Psychological Association.

Wright, S., Day, A., \& Howells, K. (2009). Mindfulness and the treatment of anger problems. Aggression and Violent Behavior, 14, 396-401. https://doi.org/10.1016/j.avb.2009.06.008

Xu, T., Zhu, H., Zhao, X., Liu, Q., Zhong, H., Chen, E., \& Xiong, H. (2016). Taxi Driving Behavior Analysis in Latent Vehicle-to-Vehicle Networks : A Social Influence Perspective. In KDD'16. San Francisco.

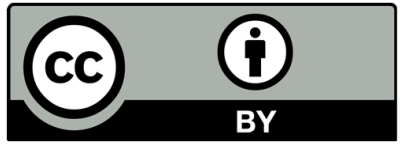

(C) 2021 by the authors; licensee Growing Science, Canada. This is an open access article distributed under the terms and conditions of the Creative Commons Attribution (CC-BY) license (http://creativecommons.org/licenses/by/4.0/). 